\title{
Mutações genéticas, métodos diagnósticos e terapêuticas relacionadas à hemocromatose hereditária
}

\author{
Karina Marini Aguiar * \\ Thalles Danylo Souza Colares \\ Mauro Aparecido de Sousa Xavier \\ Alessandra Rejane Ericsson de Oliveira Xavier \\ Universidade Estadual de Montes Claros \\ Avenida Rui Braga s $/ n^{\circ}$, Vila Mauriceia, Campus Universitário \\ CP 126, CEP 39401-089, Montes Claros $\square$ MG, Brasil \\ * Autor para correspondência \\ k_marini@hotmail.com
}

Submetido em 09/07/2013

Aceito para publicação em 02/12/2013

\section{Resumo}

A hemocromatose hereditária é uma doença genética relacionada a diversos distúrbios do metabolismo do ferro e uma das causas mais importantes da sobrecarga de ferro. Os avanços técnicos e científicos obtidos nas últimas décadas, principalmente com o desenvolvimento da biologia molecular, têm contribuído para o maior conhecimento do metabolismo do ferro e dos principais fatores relacionados à sua regulação, bem como dos distúrbios que podem resultar em déficit ou sobrecarga. A identificação de alguns genes e suas mutações auxiliou no entendimento dos mecanismos regulatórios responsáveis pela manutenção da homeostase desse nutriente essencial para numerosos processos bioquímicos. Assim, esta revisão aborda aspectos relacionados ao ferro, seu metabolismo e as causas da sobrecarga, particularmente a desenvolvida pela hemocromatose hereditária. Ainda em relação a essa doença, apresenta-se diagnóstico, orientações sobre o tratamento e mutações mais frequentes.

Palavras-chave: Diagnóstico molecular; Gene HFE; C282Y; H63D; Sobrecarga de ferro

\section{Abstract}

Genetic mutations, diagnostic methods, and therapies related to hereditary haemochromatosis. Hereditary haemochromatosis is a genetic disease related to various iron metabolism disorders and a major cause of iron overload. The technical and scientific advances obtained over the last decades, particularly with the development of molecular biology, have contributed to greater knowledge on iron metabolism and the main factors related to its regulation, as well as the disorders that can result in deficit or overload. The identification of some genes and their mutations has helped to understand the regulatory mechanisms responsible for maintaining the homeostasis of such an essential mineral for several biochemical processes. Thus, this review addresses aspects related to iron, its metabolism and the causes for overload, particularly that deriving from hereditary haemochromatosis. Also with regard to this disease, we present diagnosis, guidance on treatment, and most frequent mutations.

Key words: C282Y; Iron overload; H63D; HFE gene; Molecular diagnosis 


\section{Introdução}

A hemocromatose hereditária $(\mathrm{HH})$ é uma doença autossômica recessiva caracterizada pelo aumento de absorção intestinal de ferro. Na ausência de intervenção terapêutica o acúmulo de ferro nos tecidos pode ocasionar lesões nos órgãos gerando cirrose hepática, cardiopatias, diabetes, artrite, hipogonadismo e pigmentações na pele (VILLANI et al., 2010). A maioria dos pacientes com HH é portador de mutações no gene $H F E$ associado com a regulação da homeostase do ferro e desenvolvimento da $\mathrm{HH}$. Estudos brasileiros estimam que a prevalência da mutação C282Y no gene $H F E$, é de três a oito vezes menor em indivíduos brasileiros do que a observada em indivíduos caucasianos do norte europeu, enquanto a frequência das mutações H63C e S65C é semelhante entre essas duas populações (BUENO et al., 2006; OLIVEIRA et al., 2006; CANÇADO et al., 2007a).

Os avanços técnicos e científicos obtidos nas últimas décadas, particularmente com o desenvolvimento da biologia molecular, permitiram maior conhecimento do metabolismo normal do ferro, dos principais fatores relacionados à sua regulação bem como dos distúrbios que podem resultar em deficiência ou sobrecarga de ferro (ANDREWS; LEVY, 1998; ANDREWS, 1999; BRITTENHAM et al., 2000; AJIOKA; KUSHNER, 2002). Estes avanços serão capazes de prevenir o aparecimento de complicações orgânicas graves e, até mesmo, reverter possíveis lesões orgânicas funcionais já estabelecidas, proporcionando melhor qualidade de vida e maior sobrevida ao doente portador de HH (CAMASHELLA; PIPERNO, 1997; BURKE et al., 1998; BURT et al., 1998; MCCULLEN et al., 2002).

Devido ao crescente número de publicações demonstrando a importância do estudo da hemocromatose hereditária, de sua gravidade ser previsível, e, portanto, o fato de ser considerada um problema de saúde pública, faz-se necessário a realização de estudos que tenham como objetivo o diagnóstico precoce desta enfermidade. Deste modo, manifestações clínicas graves serão evitadas aumentando a expectativa de vida dos pacientes.

\section{Ferro e metabolismo}

O ferro é um dos micronutrientes mais estudados e melhor descritos na literatura, desempenhando importantes funções no metabolismo humano, tais como transporte e armazenamento de oxigênio, reações de liberação de energia na cadeia de transporte de elétrons, conversão de ribose a desoxirribose, co-fator de algumas reações enzimáticas e inúmeras outras reações metabólicas essenciais (CALADO et al., 2001; CANÇADO; CHIATTONE, 2002; OLIVARES; WALTER, 2004; ARAUJO, 2006; CANÇADO et al., 2007b; MOUSINHO-RIBEIRO et al., 2008; BRASSELAGNEL et al., 2010). A concentração do ferro é bem controlada, e existem várias proteínas, células e hormônios que participam da sua homeostasia e são essenciais para o equilíbrio deste mineral no organismo (SANTOS et al., 2009; GROTTO, 2010). As principais células envolvidas no processo da homeostasia são: os enterócitos, os eritroblastos, os macrófagos, e os hepatócitos. A maior parte do ferro corporal originase do ferro dietético no estado férrico $\left(\mathrm{Fe}^{3+}\right)$ que é convertido na forma ferrosa $\left(\mathrm{Fe}^{2+}\right)$. E após ingestão é absorvido predominantemente no duodeno e no jejuno pelos enterócitos (CALADO et al., 2001; SANTOS et al., 2009).

Para que haja essa conversão, há participação de uma proteína redutora chamada citocromo $\mathrm{b}$ duodenal (duodenal cytochrome b-DcytB) que então transporta o ferro para os enterócitos duodenais por meio da proteína DMT1(proteína transportadora de metais divalentes 1) (ANDERSON et al., 2009). Aparentemente, a internalização, do ferro- heme para o interior da célula do enterócito é feita pela proteína transportadora do heme-1, HCP1 (heme carrier protein). Alguns estudos demonstraram que esta proteína também transporta o folato de maneira até mais eficiente que o heme (QIU et al., 2006).

Dentro da célula então, o ferro é liberado da protoporfirina pela heme-oxigenase (HO), podendo ter dois possíveis destinos dependendo da demanda. Se a necessidade for baixa ele permanecerá no enterócito capturado e armazenado pela ferritina e será eliminado quando ocorrer descamação do epitélio 
intestinal. Se houver necessidade pelo organismo, ele será transportado através da membrana basolateral para fora do enterócito em direção ao plasma onde será transportado pela transferrina (Tf) (ANDERSON et al., 2009). A transferrina (Tf) é uma glicoproteína sintetizada e excretada pelo fígado, responsável pelo transporte do ferro entre os locais de absorção, estoque e utilização. Além de solubilizá-lo, a Tf atenua sua reatividade e facilita a sua liberação para as células. Essa transferência do mineral da corrente sanguínea para os tecidos se dá em função da ligação da transferrina a receptores específicos na superfície da membrana celular (MACHADO et al., 2005). Assim, o ferro por meio do mediador ferroportina, responsável pelo influxo de ferro através da membrana basolateral dos enterócitos para a corrente sanguínea, é transportado na forma de $\left(\mathrm{Fe}^{2+}\right)$ e oxidado a $\left(\mathrm{Fe}^{3+}\right)$ pela hefestina (Heph), uma oxidase semelhante à ceruloplasmina sérica, responsável por essa conversão (ATANASIU et al., 2006).

A ferroportina é regulada pela hepcidina, hormônio que tem a função primordial de participar na regulação do ferro. Quando as reservas de ferro estão baixas, a produção de hepcidina é suprimida e as moléculas de ferroportina transportam o ferro para a transferrina no plasma (GABRIEL et al., 2011). Ou seja, a hepcidina é capaz de se ligar a ferroportina e induzir a sua internalização, ubiquitinação e degradação (RAMEY et al., 2010). Ao contrário, o aumento na produção de hepcidina bloqueia a atividade da ferroportina em macrofágos e enterócitos, levando o acúmulo de ferro no retículo endotelial e reduz a quantidade de ferro absorvido pela dieta (GANZ, 2006).

Nos eritroblastos, o mecanismo de captação do complexo ferro-transferrina pela célula é realizado pelo receptor de transferrina 1 (TfR1), uma vez que esses precursores eritroides possuem o maior números de receptores. O complexo transferrina -TfR1 é incorporado por meio da endocitose e transportado para um endossoma ácido, onde ocorre a liberação do ferro (SANTOS et al., 2009). Ocorre a ferroredutase pela proteína redutora STEAP3 (six-transmenbrane epithelial antigen of prostate 3) e o ferro transportado para fora do endossomo através da DMT1. Subsequentemente tem-se o transporte do ferro para as mitocôndrias com a síntese do grupo heme formando a hemoglobina, ou estocado na ferritina em células não eritroides (SANTOS et al., 2009).

Nos macrófagos acontece a reciclagem do ferro presente no grupo heme para atender a quantidade necessária de ferro na sua produção diária, por meio do processo de fagocitose dos enterócitos senescentes. Este processo permite a reciclagem de cerca de $20-25 \mathrm{mg}$ de ferro por dia, quantidade essa suficiente para suprir a necessidade diária de ferro requerido para a eritropoiese na medula óssea (IOLASCON et al., 2009).

A molécula heme é catabolizada por um complexo enzimático ancorado à membrana do retículo endoplasmático, o qual compreende a NADPHcitocromo-c-redutase, a heme-oxigenase (HO) e a biliverdina redutase. Assim, o ferro liberado pelo catabolismo do heme pode ser tanto reciclado de volta ao plasma, através da ferroportina ou retido pela ferritina (FURUYAMA et al., 2007). Após a exportação pela ferroportina, o $\mathrm{Fe}^{2+}$ será oxidado pela hefestina, sintetizada no fígado. $\mathrm{O} \mathrm{Fe}^{3+}$ será transportado pela transferrina até os locais onde será reutilizado, predominantemente na medula óssea (GROTTO, 2008). Um mecanismo fisiológico conhecido relacionado à degradação do grupo heme é desempenhado pela enzima heme-oxigenase. Essa clivagem resulta na formação do monóxido de carbono (CO), $\left(\mathrm{Fe}^{2+}\right)$, e biliverdina (RAMEY et al., 2010).

\section{Sobrecarga de ferro}

O ferro é um elemento essencial para a vida e participa de numerosas funções estruturais e metabólicas nas células. Contudo, o seu acúmulo pode ser tóxico ao organismo e ocasionar hemocromatose. Esta pode ser resultado de defeitos genéticos ou devida a complicações de doenças hepáticas e certas anemias (BONINIDOMINGOS, 2006).

Em condições normais, o conteúdo total de ferro no organismo é muito estável: cerca de 4 a 5 g. Entretanto, nos pacientes sintomáticos com hemocromatose, os estoques do metal situam-se entre 20 e $40 \mathrm{~g}$, como consequência da hiperabsorção intestinal muito acima das necessidades orgânicas, mesmo que a ingestão 
dietética seja em quantidade normal (SOUZA et al., 2001).

O mecanismo exato responsável por essa absorção aumentada de ferro não é ainda bem conhecido. Aceitase que decorra da acentuação do transporte intestinal dos enterócitos para a corrente sanguínea, provavelmente em consequência da programação equivocada das células duodenais superficiais, quando estas ainda se encontram nas criptas. Isso faz com que elas captem ferro mais avidamente, como se houvesse uma deficiência orgânica do mesmo. Gera-se, portanto, deposição excessiva de ferro nas células parenquimatosas, em especial do fígado, do pâncreas e do coração, que acaba por estimular a peroxidação lipídica e a produção de radicais livres, promovendo lesão celular e fibrose progressiva (SOUZA et al., 2001).

Esta sobrecarga de ferro pode ser classificada em primária ou secundária. A primária está relacionada à herança genética, por alterações nos genes de proteinas envolvidas na homeostase. Dentre as causas primárias, encontra-se o grupo das HHs relacionadas ao gene HFE (tipo 1) - com mutações em C282Y/C282Y, C282Y/ H63D; outras mutações HFE e as não relacionadas a mutação HFE tais como: Hemojuvelina (HJV) (tipo 2, subtipo A), Hepcidina (HAMP) (Tipo 2, subtipo B), Receptor de transferrina 2 (TfR2) (Tipo 3), Ferroportina (SLC40A1) (Tipo 4) e sobrecarga de ferro africana. A sobrecarga secundária é observada em doenças congênitas ou adquiridas e envolve as anemias com sobrecarga de ferro como a: Thalassemia Maior, Anemia Sideroblástica, Anemia Hemolítica Crônica, Anemia Aplástica, Anemia responsiva à Piridoxina. Também existe a sobrecarga parenteral, decorrente de transfusões de glóbulos vermelhos, que são: Ferro- por meio da injeção de dextran, hemodiálise por longo tempo e por doenças hepáticas crônica, hepatite $\mathrm{B}$, hepatite $\mathrm{C}$, doença hepática alcoólica, doença gordurosa não alcoólica (FAHIM; AHMED, 2011).

\section{Hemocromatose}

A doença foi primeiramente descrita por Armand Trousseau, em 1865, na França, com um caso de diabetes de bronze e cirrose. Em 1889, Von Recklinghausen, patologista alemão, usou o termo $\square$ hemocromatose $\square$ após descobrir que os pacientes tinham uma pigmentação nas células do fígado provocada pelo ferro. Sheldon (1935, apud SIDDIQUE; KOWDLEY, 2012) tornou claro que a doença era hereditária e causada por excesso de depósitos de ferro nos tecidos e a associou com desordens do metabolismo do ferro (PIETRANGELO, 2004; 2006; SIDDIQUE; KOWDLEY, 2012). Com o decorrer dos estudos, Simon et al. (1976) definiram a incidência e transmissão genética da doença que parecia estar ligada ao complexo HLA e mapeado próximo ao lócus do HLA-A. Foi então em 1996, que Feder identificou o gene da $H F E$, para a mutação (C282Y) que estava presente na maioria dos pacientes com HH (PIETRANGELO, 2004; 2006; SIDDIQUE; KOWDLEY, 2012). Esta alteração hereditária no gene da $\mathrm{HH}$ leva ao acúmulo progressivo do ferro nas células parenquimatosas do fígado, pâncreas e coração (VILLANI et al., 2010). Com a evolução pode-se observar danos estruturais e funcionais aos órgãos comprometidos (BACON, 2001; VILLANI et al., 2010; BACON et al., 2011). Em caucasianos ela se mostra, dentre as identificadas, a mais comum, afetando um em cada 200 a 400 indivíduos descendentes da região do Norte Europeu (BACON et al., 2011). A sintomatologia da doença envolve queixas frequentes como fadiga, dor abdominal, hiperpigmentação da pele, alopecia, impotência sexual, perda ponderal, hepatoesplenomegalia, e artralgia causada pela artropatia, insuficiência cardíaca, arritmias, cirrose hepática e diabetes estão associadas a um mau prognóstico (ZOLLER; COX, 2005; CANÇADO; CHIATTONE, 2010).

\section{Diagnóstico}

Uma vez identificado o paciente com suspeita clínica da doença, é necessário investigar os principais parâmetros do metabolismo do ferro, e confirmar com testes mais específicos. Assim, devem ser avaliadas as concentrações séricas de ferritina, transferrina, ferro sérico e saturação da transferrina ou capacidade total de ligação de ferro (ZOLLER; COX, 2005; SIDDIQUE; KOWDLEY, 2012). Além disso, devem ser investigadas as mutações relacionadas à homeostase do ferro por meio de testes genéticos (SANTOS et al., 2009). 
A saturação de transferrina é considerada o teste de rastreamento inicial, por ser mais sensível e precoce na detecção da sobrecarga do ferro presente na $\mathrm{HH}$ (SIDIQUE; KOWDLEY, 2012). Este teste apresenta uma sensibilidade acima de $90 \%$ e está frequentemente elevado em adultos jovens antes do desenvolvimento da sobrecarga do ferro e aumento da ferritina (BACON, 2001; SOUZA et al., 2001; VILLANI et al., 2010). É calculado a partir do quociente entre o ferro sérico e a capacidade de ligação do ferro, multiplicado por 100 . O seu valor normal situa-se entre $30 \%$ a $40 \%$, sendo geralmente maior que $60 \%$ nos homens e maior que $50 \%$ nas mulheres com a hemocromatose clínica (SOUZA et al., 2001). Em alguns laboratórios, a capacidade total de ligação do ferro é calculada a partir da soma do ferro sérico e da capacidade de ligação de ferro insaturado, enquanto em outros, ele é calculado indiretamente a partir da concentração da transferrina no soro. (BACON, 2001). A faixa normal de capacidade total de ligação do ferro (CTLF) varia entre 45 e $70 \mathrm{mmol} / \mathrm{L}$ (250$390 \mathrm{mg} / \mathrm{dL}$ ). Em função da reduzida especificidade e sensibilidade da concentração do ferro sérico $(\mathrm{FeS})$ e da CTLF, costuma-se considerar a relação entre as duas medidas (FeS/CTLF) que é a saturação da transferrina (ST) (PAIVA et al., 2000).

A ferritina por ser uma proteína de fase aguda, está também aumentada em doenças inflamatórias ou malignas. No entanto, pode ser um excelente preditor para evolução da doença hemocromatose, nas complicações como cirrose e fibrose, porém não tem especificidade se utilizado sozinho como teste de rastreamento (SIDDIQUE; KOWDLEY, 2012). Na ausência de processos inflamatórios, vários estudos de famílias com hemocromatose têm demonstrado que a concentração de ferritina sérica fornece uma correlação com o grau valioso das reservas de ferro do organismo. $\mathrm{Na}$ maioria das circunstâncias, essa ferritina sérica fornece uma confirmação adicional da importância de uma saturação de transferrina elevada em homozigotos C282Y (BACON et al., 2011).

Um hemograma completo pode excluir a sobrecarga do ferro das anemias, como anemia sideroblástica, talassemia e outras hemoglobinopatias, em especial em pacientes sul-africano ou de origem europeia. Dosagem da albumina, bilirrubina, e estudos de coagulação, bem como as atividades de ALT (Alanina transaminase) e AST (Aspartato transaminase), irá fornecer informações sobre a função hepática e revelar a presença de lesão hepatocelular (ZOLLER; COX, 2005).

A dosagem do ferro sérico não é tão específica para o diagnóstico da hemocromatose uma vez que existem variações intra e interlaboratoriais e, fisiologicamente, há variações diárias e circadianas, além da elevação pós-prandial. $\mathrm{O}$ teste apresenta baixa sensibilidade e especificidade. O nível normal é aproximadamente 20 $\mu \mathrm{mol} / \mathrm{L}$, um pouco mais elevado no sexo masculino e quando há sobrecarga, encontra-se na faixa de superior a $30 \mu \mathrm{mol} / \mathrm{L}$ (VILLANI et al., 2010).

A genotipagem para detecção das mutações é um teste útil no diagnóstico da hemocromatose hereditária. Podem ser detectadas por meio da análise de Polimorfismos de Fragmentos de Restrição, utilizando a técnica de PCR (reação em cadeia da polimerase) e enzimas de restrições específicas. É uma técnica que permite a amplificação de regiões específicas do DNA. E consiste em três fases: desnaturação, em que por aquecimento, há separação da dupla fita do DNA; anelamento: os oligonucleotídeos iniciadores (primers) se helicoidizam a uma sequência alvo de DNA. Juntos, os primers flanqueiam a sequência alvo; e a extensão da cadeia de DNA, através da ação da Taq polimerase (enzima extraída de uma bactéria termofílica, a Thermus aquaticus). No final da reação o produto amplificado da PCR pode ser detectado através da eletroforese (VILLANI et al., 2010).

Com o avanço das análises de mutações, a biópsia hepática tornou-se uma ferramenta menos importante para o diagnóstico da hemocromatose. Ela deve ser considerada apenas com a finalidade de determinar a presença ou ausência da fibrose avançada ou cirrose, que não possui valor diagnóstico para hemocromatose (BACON et al., 2011; SIDDIQUE; KOWDLEY, 2012).

Os testes de imagem como tomografia computadorizada e ressonância magnética contribuem muito para a avaliação de hemocromatose. A ressonância magnética faz uma quantificação não invasiva de armazenamento de ferro demonstrando uma clara 
vantagem sobre a quantificação química das amostras de biópsia hepática. A sensibilidade da tomografia computadorizada para a quantificação de ferro hepático é menor do que a de ressonância magnética, mas a hipodensidade do parêquima hepático à tomografia pode ser um sinal de alerta de sobrecarga de ferro. Com contraste trifásico esses testes são importantes para o diagnóstico de suspeita de carcinoma hepatocelular, uma complicação da hemocromatose, mesmo com o fígado não cirrótico (ZOLLER; COX, 2005).

Outro parâmetro utilizado para a quantificação do ferro no miocárdio é a do T2*. A doença cardíaca é a principal causa de morte em pacientes com sobrecarga de ferro. A quantificação de T2* tem mostrado ser um método promissor para o diagnóstico precoce de sobrecarga de ferro neste local e demonstrado como melhor método preditivo de disfunção cardíaca (ANDERSON et al., 2001; CANÇADO, 2007).

O fígado é o principal sítio de armazenamento do ferro. Aproximadamente $90 \%$ do excesso de ferro deposita-se neste órgão. $\mathrm{Na}$ ausência de tratamento adequado, o excesso armazena-se gradativamente em vários órgãos ou tecidos, principalmente fígado, baço, miocárdio, glândulas endócrinas e medula óssea, ocasionando lesão celular e tecidual, fibrose e insuficiência funcional (ZOLLER; COX, 2005; CANÇADO, 2007; SANTOS et al., 2009). O desenvolvimento da lesão hepática nos pacientes com HH está relacionado ao acúmulo progressivo de ferro hepático. A concentração de ferro hepático aumenta com a idade na maioria dos pacientes homozigotos. Então, nos pacientes com mais de 40 anos, a concentração hepática de ferro provavelmente excede $10.000 \mu \mathrm{g} / \mathrm{g}$ de fígado seco e a biópsia hepática revela fibrose ou cirrose. A observação do aumento da concentração de ferro hepático com a idade levou ao desenvolvimento do índice de ferro hepático (divisão do conteúdo de ferro hepático em $\mu \mathrm{mol} / \mathrm{g}$ de fígado seco pela idade). Valores superiores a 1,9 são encontrados em $85 \%$ a $90 \%$ dos pacientes e é capaz de distinguir a homozigose para HH. O grau de sobrecarga de ferro tem então, impacto direto sobre a expectativa de vida nestes pacientes (SALLIE et al., 1991; SANTOS et al., 2009).
Mutações em genes descritos na literatura relacionados à hemocromatose

A hemocromatose foi classificada com base nas características clínicas, bioquímicas e genética segundo a Online Mendelian Inheritance in Man (OMIM) em cinco tipos:

- Tipo 1: mais clássica e mais frequente. É causada por mutações no gene $H F E$, descrita por Feder et al. (1996), e está localizado no cromossomo 6p21.3. Representa mais de $90 \%$ dos casos da doença e afeta populações caucasianas.

- Tipo 2: é representada pela hemacromatose juvenil com mutações no gene hemojuvelina (HJV) e mutações no gene da hepcidina (HAMP) A mutação no gene $H J V$ está localizada no cromossomo 1q21 e é considerada tipo $2 \mathrm{~A}$. Já a mutação no gene HAMP, um outro subtipo encontra-se no cromossomo 19q13 e é chamado de tipo $2 \mathrm{~B}$.

- Tipo 3: hemocromatose do receptor de transferrina 2. A mutação ocorre no gene $T f R 2$, localizado no cromossomo 7q22. Clinicamente é semelhante à hemacromatose da HFE, que é o tipo 1.

- Tipo 4: doença da ferroportina, com mutações no gene ferroportina (SLC4OA1), localizado no cromossomo 2q32. Pode ser dividida de duas formas. O subtipo A é caracterizado por níveis baixos da saturação de transferrina e com depósito de ferro nos macrófagos e o subtipo B é observado quando se tem níveis elevados de saturação de transferrina e depósito de ferro nos hepatócitos, semelhante com o tipo 1. (PIETRANGELO, 2006; FRANCHINI, 2006, BRISSOT; DE BELS, 2006; SANTOS et al., 2012).

- Tipo 5: representa outras formas hereditárias raras de sobrecarga de ferro. Pode ocorrer mutações no gene da ceruloplasmina, com apresentações hematológicas e, ou neurológicas. No gene da transferrina, essa é expressa pela anemia com deficiência severa do ferro e sobrecarga de ferro parenquimal. Ou recentemente relatado mutação no gene DMT1 (transportador de metal dicvalente 1) que também é responsável pela anemia ferropriva e excesso de ferro hepático (BRISSOT; DE BELS, 2006). 


\section{Mutações no gene HFE}

A hemocromatose associada ao gene $H F E$ é uma herança autossômica recessiva, com penetrância variável. $\mathrm{Na}$ maioria dos casos se manifesta entre a faixa etária dos 40 aos 50 anos de idade e as características fenotípicas são mais comuns no sexo masculino (SIDDIQUE; KOWDLEY, 2012). As mutações mais frequentes encontradas no gene $H F E$ são p.C282Y, p.H63D e p.S65C, porém foram descritas outras mutações raras tais como: pV53M, p.V59M, p.Q127H, p.R330M, p.I105T, p.G93R, p.Q283P (SANTOS et al., 2012).

As mutações p.C282Y e p.H63D foram descritas por Feder et al. (1996). Na p.C282Y ocorre a substituição do aminoácido tirosina pela cisteína na posição 282 , resultante da troca da base $\mathrm{G}$ para A no nucleotídeo 845 e a p.H63D pela substituição da histidina pelo ácido aspártico na posição 63 decorrente a troca da base $\mathrm{G}$ para C no nucleotídeo 187 no gene $H F E$ (SASSI et al., 2004; FRANCINI, 2006; CUKJATI et al., 2007).

A terceira mutação S65C foi descrita por Mura et al. (1999), porém não foi totalmente investigada e existe pouca informação sobre sua frequência genética (FRANCHINI, 2006). Consiste na troca da serina por cisteína na posição 65 da proteína HFE devido à troca da base A para T no nucleotídeo 193 (CUKJATI et al., 2007; SANTOS et al., 2009).

Aproximadamente $85-90 \%$ dos pacientes com fenótipo típico da hemocromatose clássica são homozigotos C282Y e cerca de 3-5\% são heterozigotos C282Y/H63D. A prevalência de homozigotos C282Y é de um em 250 pessoas da população em geral e cerca de um em 200 pessoas descentes do norte-europeu (FRANCHINI, 2006). A mutação C282Y é a mais importante associada às características clínicas e possui diferentes frequências em variadas populações. Esta mutação, por exemplo, tem uma frequência de $100 \%$ em pacientes australianos com hemocromatose e em italianos de 64\% (FRANCHINI, 2006; BUENO et al., 2006). No Canadá, Estados Unidos, Inglaterra, França, Alemanha, Portugal entre outros países de origem caucasoide, cerca de $90 \%$ a $95 \%$ dos pacientes com hemocromatose hereditária apresentam homozigose para a mutação C282Y; porém esta relação sofre variações nas populações (JACKOWISKI et al., 2004).
A presença de mutação $\mathrm{C} 282 \mathrm{Y}$ homozigótico indica a existência de alteração genética e maior predisposição ao desenvolvimento do fenótipo da doença, mas não é suficiente para o diagnóstico da hemocromatose. Esta situação se deve ao fato de que a penetrância do alelo mutante e a expressão fenotípica da doença são incompletas, tornando bastante difícil prever quem desenvolverá ou não o quadro clínico da doença (SANTOS et al., 2009; SIDDIQUE; KOWDLEY, 2012).

No Brasil, os estudos de prevalência da hemocromatose são ainda muito escassos, porém é possível encontrar um alelo mutante em $4 \%$ a $7 \%$ da população geral da região Nordeste do país. Tendo em vista a heterogeneidade genética observada no Brasil, devido à grande mistura étnica de negroides, caucasoides e ameríndios, a frequência da mutação C282Y pode sofrer variação comparada a populações em outros países. Além disso, por ser um país geograficamente grande, nota-se a ocorrência de diferentes frequências regionais devido às diferentes etnias que colonizaram cada região (JACKOWISKI et al., 2004).

A mutação H63D é mais comum comparada a C283Y com uma frequência de $10-20 \%$ na população europeia. Somente 0,5 a $2 \%$ dos portadores de heterozigose $\mathrm{C} 282 \mathrm{Y} / \mathrm{H} 63 \mathrm{D}$ desenvolvem a sobrecarga de ferro (SIDDIQUE; KOWDLEY, 2012). Assim, apenas a mutação H63D não possui uma forte associação com a sobrecarga do ferro, embora a heterozigose seja responsável por $6 \%$ dos casos em europeus e $4 \%$ americanos (BUENO et al., 2006). Além disso, a homozigose H63D é reportada associada ao fenótipo típico da hemocromatose em casos raros, mas essa associação ocorre com comorbidades, por exemplo, alcoolismo, ou síndrome metabólica (BRISSOT; DE BELS, 2006).

Estudos brasileiros em pessoas com sobrecarga de ferro ou hemocromatose demonstraram que menos de um terço possuem mutação homozigótica para $\mathrm{C} 282 \mathrm{Y}$ ou heterozigótica para $\mathrm{C} 282 \mathrm{Y} / \mathrm{H} 63 \mathrm{D}$. A frequência de ambas é menor em brasileiros quando comparada a Europeus e Norte-Americanos saudáveis (BITTENCOURT et al., 2009). 
A mutação S65C bem como a homozigose para H63D foi recentemente associada a uma moderada sobrecarga de ferro (BITTENCOURT et al., 2009). Alguns estudos na população do mediterrâneo encontraram uma frequência de 0,15\% e no Reino Unido 0,9\% (BUENO et al., 2006). No estudo de Bueno et al. (2006), em doadores de sangue em São Paulo, Brasil, encontraram uma frequência genética da mutação $\mathrm{S} 65 \mathrm{C}$ similar a C282Y. Entretanto, em 35 pacientes brasileiros com sobrecarga de ferro a mutação $\mathrm{S} 65 \mathrm{C}$ não foi observada (BUENO et al., 2006).

\section{Tratamento}

O tratamento da hemocromatose hereditária é obrigatório em pacientes sintomáticos ou quando os níveis séricos de ferritina estão significativamente aumentados, por causa do risco de fibrose hepática. Sendo assim, é recomendado a flebotomia terapêutica por ser mais segura, eficaz e mais econômica. Consiste na remoção de cerca de 400 a $500 \mathrm{ml}$ de sangue, isto é aproximadamente de 200 a $250 \mathrm{mg}$ de ferro. O período do tratamento depende da carga de ferro do paciente que pode ser semanalmente ou por um período maior, evitando assim os danos de órgãos e a melhora da sobrevida (CAMASCHELLA; PIPERNO, 1997; PIETRANGELO, 2006; SANTOS et al., 2009).

Quando a flebotomia não é viável, por exemplo, pacientes com anemia e/ou que não toleram ou recusam a remoção do excesso de ferro por este meio, pode-se lancar mão do uso de quelantes de ferro, eles demonstraram ser seguro e eficazes. A desferroxamina subcutânea ou mais recentemente, um novo quelante denominado deferasirox, administrado por via oral e em uma única dose diária, foi aprovado para pacientes com sobrecarga transfusional (SANTOS et al., 2009; CANÇADO; CHIATTONE, 2010; NAGLER et al., 2011).

\section{Considerações finais}

No diagnóstico da hemocromatose hereditária, devem-se excluir as causas secundárias, isto é, aquelas observadas em doenças congênitas ou adquiridas que cursam com anemia hemolítica e/ou eritropoiese ineficaz e requerem múltiplas transfusões de hemácias, além disso, a expressão fenotípica da sobrecarga do ferro e as repercussões desta no organismo devem prevalecer à expressão genotípica. (SANTOS et al., 2009). Logo, pesquisa de mutações sejam elas nos genes $H F E$ ou HJV, HAMP, TfR2 e SlC40A1 devem ser realizadas para colaborarem com o entendimento da fisiopalogia da doença.

Com o avanço da biologia molecular, hoje é possível detectar alterações genéticas específicas responsáveis por várias doenças, até mesmo antes, de o indivíduo manifestar sintomas. É importante prevenir a sobrecarga de ferro que ocorre silenciosamente e detectar indivíduos ainda saudáveis. Pois, mais tarde poderão apresentar manifestações clínicas e susceptibilidade aumentada para algumas doenças hereditárias.

\section{Referências}

AJIOKA, R. S.; KUSHNER, J. P. Hereditary hemochromatosis. [Review] Seminars in Hematology, Philadelphia, v. 39, n. 4, p. 235-241, 2002.

ANDERSON, G. J.; FRAZERA, D. M.; MCLAREN, G. D. Iron absorption and metabolism. Current Opinion in Gastroenterology, Baltimore, v. 25, n. 2, p. 129-135, 2009.

ANDERSON, L. J.; HOLDEN, S.; DAVIS, B.; PRESCOTT, E.; CHARRIER, C. C.; BUNCE, N. H.; FIRMIN, D. N.; WONKE. B.; PORTER, J.; WALKER, J. M.; PENNELL, D. J. Cardiovascular T2-star $(\mathrm{T} 2 *)$ magnetic resonance for the early diagnosis of myocardial iron overload. European Heart Journal, London, v. 22, n. 23, p. 2171-2179.

ANDREWS, N. C. Disorders of iron metabolism. New England Journal of Medicine, Massachusetts, v. 341, n. 26, p. 1986-1995, 1999.

ANDREWS. N. C.; LEVY, J. E. Iron is hot: an update on the pathophysiology of hemochromatosis. Blood Journal, Washington, v. 92, n. 6, p. 1845-1851, 1998.

ARAUJO, C. P. L. C. Ferropenia em doadores de sangue. Revista Médica da Santa Casa de Maceió, Maceió, v. 1, n. 1, p. 30-35, 2006.

ATANASIU, V.; MANOLESCU, B.; STOIAN, I. Hepcidin $\square$ central regulator of iron metabolism. European Journal of Haematology, Copenhagen, v. 78, n. 1, p. 1-10, 2006.

BACON, B. R. Hemochromatosis: diagnosis and management. Gastroenterology, Philadelphia, v. 120, n. 3, p. 718-725, 2001.

BACON, B. R.; ADAMS, P. C.; KOWDLEY, K. V.; POWELL, L. W.; TAVILL, A. S. Diagnosis and management of hemochromatosis: 2011 practice guideline by the American Association for the Study of Liver Diseases. Hepatology, Baltimore, v. 54, n. 1, p. 328-343, 2011. 
BITTENCOURT, P. L.; MARIN, M. L. C.; COUTO, C. A.; CANÇADO, E. L. R.; CARRILHO, F. J.; GOLDBERG, A. C. Analysis of HFE and non-HFE gene mutation in Brazilian patients with Hemochromatosis. Clinics, São Paulo, v. 64, n. 9, p. 837-841, 2009.

BONINI-DOMINGOS, C. R. Hemocromatose hereditária e as mutações no gene HFE. Revista Brasileira de Hematologia e Hemoterapia, São José do Rio Preto, v. 28, n. 4, p. 239-245, 2006. BRASSE-LAGNEL， C.; POLI, M.; LESUEUR, C.; GRANDCHAMP, B.; LAVOINNE, A.; BEAUMONT,C.; BEKRI, $\mathrm{S}$. Immunoassay for human serum hemojuvelin. Haematologica, Pavia, v. 95, n. 12, p. 2031-2037, 2010.

BRISSOT, P., DE BELS, F. Current approaches to the management of hemochromatosis. Hematology American Society of Hematology Educational Program, Washington, v. 2006, n. 1, p. 36-41, 2006.

BRITTENHAM, G. M.; WEISS, G., BRISSOT, P.; LAINÉ, F. A.; GUVADER, D.; MOIRAND, R.; DEUGNIER, Y. Clinical consequences of new insights in the pathophysiology of disorders of iron and heme metabolism. Hematology American Society Hematology Education Program, Washington, v. 2000, n. 1, p. 39-50, 2000.

BUENO, S.; DUCH, C. R.; FIGUEIREDO, M. S. Mutations in the HFE gene (C282Y, H63D, S65C) in a Brazilian population. Revista Brasileira de Hematologia e Hemoterapia, São José do Rio Preto, v. 28, n. 4, p. 293-295, 2006.

BURKE, W.; THOMSON, E.; KHOURY, M. J.; MCDONNELL, S. M.; PRESS, N.; ADAMS, P. C. Hereditary hemochromatosis: gene discovery and its implication for population based screening. Journal of the American Medical Association, Chicago, v. 280, n. 2, p. 172-178, 1998.

BURT, M. J.; GEORGE, P. M.; UPTON, J. D.; COLLETT, J. A.; FRAMPTOM, C. M.; CHAPMAN, T. M. The significance of haemochromatosis gene mutations in the general population: implications for screening. Gut, London, v. 43, n. 6, p. 830-836, 1998.

CALADO, R. T.; ALBERTO, F. L.; FALCÃO, R. P. Metabolismo do ferro. In: ZAGO, M. A.; FALCÃO, R. P.; PASQUINI, R. (Ed.). Hematologia, fundamentos e prática. São Paulo: Atheneu, 2001. p. 213-221.

CAMASCHELLA, C.; PIPERNO, A. Hereditary hemochromatosis: recent advances in molecular genetics and clinical management. [Review] Haematologica, Pavia, v. 82, n. 1, p. 77-84, 1997.

CANÇADO, R. D. Sobrecarga e quelação de ferro na anemia falciforme. Revista Brasileira de Hematologia e Hemoterapia, São José do Rio Preto, v. 29, n. 3, p. 316-226, 2007.

CANÇADO, R. D.; CHIATTONE, C. S. Anemia de doença crônica. Revista Brasileira de Hematologia e Hemoterapia, São José do Rio Preto, v. 24, n. 2, p. 127-136, 2002.

CANÇADO, R. D.; CHIATTONE, C. S. Current approach to hereditary hemochromatosis. Revista Brasileira de Hematologia e Hemoterapia, São José do Rio Preto, v. 32, n. 6, p. 469-475, 2010.

CANÇADO, R. D.; FONSECA, L. G.; CLARO, M. R. C.; TAJARA, F. S.; LANGHI-JÚNIOR, D. M.; CHIATTONE, C. S. Avaliação laboratorial da deficiência de ferro em doadoras de sangue. Revista Brasileira de Hematologia e Hemoterapia, São José do Rio Preto, v. 29, n. 2, p. 153-159, 2007 b.
CANÇADO, R. D.; GUGLIELMI, A. C. O.; VERGUEIRO, C. S. V., ROLIM, E. G.; FIGUEIREDO, M. S.; CHIATTONE, C. S. Estudo das mutações C282Y, H63D e S65C do gene HFE em doentes brasileiros com sobrecarga de ferro. Revista Brasileira de Hematologia e Hemoterapia, São José do Rio Preto, v. 29, n. 4, p. 351-360, 2007a.

CUKJATI, M.; VAUPOTIČ, T.; RUTH RUPREHT, R.; ЖURINŠERBEC, V. Prevalence of H63D, S65C and C282Y hereditary hemochromatosis gene mutations in Slovenian population by an improved high-throughput genotyping assay. BMC Medical Genetics, London, v. 8, n. 10, p. 691-699, 2007.

FAHIM, F.; AHMED, M. G. S. Iron overload. Haematology Updates, Timergara, v. 1, n. 5, p. 11-16, 2011.

FEDER, J. N.; GNIRKE, A.; THOMAS, W.; TSUCHIHASHI, Z.; RUDDY, D. A.; BASAVA, A.; DORMISHIAN, F.; DOMINGO, R.; ELLIS, M. C.; FULlAN, A.; HINTON, L. M.; JONES, N. L.; KIMMEL, B. E.; KRONMAL, G. S.; LAUER, P.; LEE, V. K.; LOEB, D. B.; MAPA, F. A.; MCCLELLAND, E.; MEYER, N. C.; MINTIER, G. A.; MOELLER, N.; MOORE, T.; MORIKANG, E.; PRASS, C.E.; QIUNTANA, L.; STARNES, S. M.; SCHATZMANN, R. C.; BRUNKE, K. J.; DRAUNA, D. T.; RISCH, N. J.; BACON, B. R.; WOLFF, R. K. A novel MHC class I-like gene is mutated in patients with hereditary haemochromatosis. Nature Genetics, New York, v. 13, p. 399-408, 1996.

FRANCHINI, M. Hereditary iron overload: update on pathophysiology, diagnosis, and treatment. American Journal of Hematology, New York, v. 81, n. 3, p. 202-209, 2006.

FURUYAMA, K.; KANEKO, K.; VARGAS, V. Heme as a magnificent molecule with multiple missions: heme determines its own fate and governs cellular homeostasis. Tohoku Journal of Experimental Medicine, Tokyo, v. 213, n. 1, p. 1-16, 2007.

GABRIEL, F. R.; SUEN, V. M. M.; MARCHINI, J. S.; OLIVEIRA, J. E. D. The metabolism of iron: a review of the literature. International Journal of Nutrology, Ribeirão Preto, v. 4, n. 2, p. 24-28, 2011.

GANZ, T. Hepcidin and its role inregulating systemic iron metabolism. Hematology American Society of Hematology Educational Program, Washington, v. 2006, n. 1, p. 29-35, 2006.

GROTTO, H. Z. W. Metabolismo do ferro: uma revisão sobre os principais mecanismos envolvidos em sua homeostase. Revista Brasileira de Hematologia e Hemoterapia, São José do Rio Preto, v. 30, n. 5, p. 390-397, 2008.

GROTTO, H. Z. W. Fisiologia e metabolismo do ferro. Revista Brasileira de Hematologia e Hemoterapia, São José do Rio Preto, v. 32, n. 2 (supl. 2), p. 8-17, 2010.

IOLASCON, A.; FALCO, L.; BEAUMONT, C. Molecular basis of inherited microcytic anemia due to defects in iron acquisitionor heme synthesis. Haematologica, Pavia, v. 94, n. 3, p. 395-408, 2009.

JACKOWISKI, D.; REBELLO, E. S.; FAUCZ, F. R. Análise da freqüência da mutação $\mathrm{C} 282 \mathrm{Y}$ na população paranaense. Revista Estudos de Biologia, Curitiba, v. 26, n. 55, p. 11-18, 2004.

MACHADO, A. A.; IZUMI, C.; FREITAS, O. Bases moleculares da absorção do ferro. Alimentos e Nutrição, Araraquara, v. 16, n. 3, p. 293-298, 2005.

MCCULLEN, M. A.; CRAWFORD, D. H. G.; HICKMAN, P. E. [Review] Screening for hemochromatosis. Clinica Chimica Acta, Amsterdam, v. 315, p. 169-186, 2002. 
MOUSINHO-RIBEIRO, R. C.; SOUSA, G. P.; NUNES, T. M.; NEVES, M. C. Impacto da doação de sangue nos depósitos de ferro do organismo de doadores. Revista Brasileira de Hematologia e Hemoterapia, São José do Rio Preto, v. 30, n. 1, p. 61-69, 2008.

MURA, C.; RAGUENES, O.; FÉREC, C. HFE mutations analysis in 711 hemochromatosis probands: evidence for S65C implications in mild form of hemochromatosis. Blood, Washington, v. 93, n. 8, p. 2502-2505, 1999.

NAGLER, M.; GREGOR, M.; WUILLEMIN, W. A. Iron chelation with deferasirox in two pacients with HFE hemochromatosis and chronic anemia. Acta Haematologica, Basel, v. 126, n. 2, p. 119121, 2011.

OLIVARES, M.; WALTER, T. Causas y consecuencias de la deficiencia de hierro. Revista de Nutrição, Campinas, v. 17, n. 1, p. 5-14, 2004.

OLIVEIRA, T. M.; SOUZA, F. P.; JARDIM, A. C. G.; CORDEIRO, J. A.; PINHO, J. R. R.; SITNIK, R.; ESTEVÃO, I. F.; BONINIDOMINGOS, C. R.; RAHAL, P. HFE gene mutations in Brazilian thalassemic patients. Brazilian Journal of Medical and Biological Research, Ribeirão Preto, v. 39, n. 12, p. 1575-1580, 2006.

PAIVA, A. A.; RONDÓ, P. H. C.; GUERRA-SHINOHARA, E. M. Parâmetros para avaliação do estado nutricional de ferro. Revista de Saúde Pública, São Paulo, v. 24, n. 4, p. 421-426, 2000.

PIETRANGELO, A. Hereditary hemochromatosis - a new look at an old disease. New England Journal of Medicine, Massachusetts, v. 350, n. 23, p. 2383-2397, 2004.

PIETRANGELO, A. Hereditary hemochromatosis. Biochimica et Biophysica Acta, Amsterdam, v. 1763, n. 7, p. 400-710, 2006.

QIU, A.; JANSEN, M.; SAKARIS, A.; SANG HEE MIN, S. H.; CHATTOPADHYAY, S.; TSAI, E.; SANDOVAL, C.; ZHAO, R.; AKABAS, M. H.; GOLDMAN, D. I. Identification of an intestinal folate transporter and the molecular basis for hereditary folate malabsorption. Cell, Riverport Lane, v. 127, n. 5, p. 917-928, 2006.

RAMEY, G.; DESCHEMIN, J-C.; DUREL, B.; CANONNEHERGAUX, F.; NICOLAS, G.; VAULONT, S. Hepcidin targets ferroportin for degradation in hepatocytes. Haematologica, Pavia, v. 95, n. 3, p. 501-504, 2010.
SALLIE, R. W.; REED, W. D.; SHILKIN, K. B. Confirmation on the efficacy of hepatic tissue iron index in differentiating genetic haemochromatosis from alcoholic liver disease complicated by alcoholic haemosiderosis. Gut, London, v. 32, n. 2, p. 207-210, 1991. SANTOS, P. C. J. L.; CANÇADO, R. D.; TERADA, C. T.; GUERRA-SHINOHARA, E. M. Alterações moleculares associadas à hemocromatose hereditária. Revista Brasileira de Hematologia e Hemoterapia, São José do Rio Preto, v. 31, n. 3, p. 192-202, 2009.

SANTOS, P. C. J. L.; KRIEGER, J. E.; PEREIRA, A. C. Molecular Diagnostic and Pathogenesis of Hereditary Hemochromatosis. International Journal of Molecular Sciences, Basel, v. 13, n. 2, p. 1497-1511, 2012.

SASSI, R.; HMIDA, S.; KAABI, H.; HAJJEJ, A.; ABID, A.; ABDELKEFI, S.; YACOUB, S.; MAAMAR, M.; MOJAAT, N.; BEN HAMED, L. B.; BELLALI, H.; A. DRIDI, A.; JRIDI, A.; MIDOUNI, B.; BOUKEF, M. K. Prevalence of C282Y and H63D mutations in the haemochromatosis $(H F E)$ gene in Tunisian population. Annales de Génétique, Paris, v. 47, n. 4, p. 325-330, 2004.

SIDDIQUE, A.; KOWDLEY, K. V. Review article: the iron overload syndromes. Alimentary Pharmacology and Therapeutics, Oxford, v. 35, n. 8, p. 876-893, 2012.

SIMON, M.; BOUREL, M.; FAUCHET, B.; GENETET, B. Association of HLA-A3 and HLA-B14 antigens with idiopathic haemochromatosis. Gut, London, v. 17, n. 1, p. 332-334, 1976.

SOUZA, A. F. M.; CARVALHO-FILHO, R. J.; CHEBLI, J. F. Hemocromatose hereditária. Relato de caso e revisão da literatura. Arquivos de Gastroenterologia, São Paulo, v. 38, n. 3, p. 194-202, 2001 .

VILLANI, K. J.; VIANA, G. C.; CARAVALHO, G. R.; GUIDINE, A. T.; CORRÊA, J. O. A.; MESQUITA, H. L. Hereditary hemochromatosis HFE gene related. Revista Interdisciplinar de Estudos Experimentais, Juiz de Fora, v. 2, n. 1, p. 14-21, 2010.

ZOLLER, H.; COX, T. M. Hemochromatosis: genetic testing and clinical practice. Clinical Gastroenterology and Hepatology, Philadelphia, v. 3, n. 10, p. 945-958, 2005. 